\title{
Hyalomma spp. ticks and associated Anaplasma spp. and Ehrlichia spp. on the Iran-Pakistan border
}

\author{
Nayyereh Choubdar ${ }^{1}$, Fateh Karimian ${ }^{1,2}$, Mona Koosha', Jalil Nejati ${ }^{3}$ and Mohammad Ali Oshaghi ${ }^{*}$ (D)
}

\begin{abstract}
Background: Anaplasmosis and ehrlichiosis are tick-borne diseases affecting humans and livestock, particularly in tropical and subtropical regions. Animal husbandry is the main activity of people on the borders of Iran and Pakistan, with thousands of cattle crossing the border each week.

Methods: PCR and sequencing of the 16S rRNA gene was used to determine the percentage and geographical distribution of the pathogens carried by Hyalomma spp. $(n=306)$ collected from 126 goats, cattle and camels in the region between November 2017 and late March 2018.

Results: In total, 1124 hard ticks including 1020 Hyalomma spp. ticks belonging to six species (Hyalomma anatolicum, Hyalomma asiaticum, Hyalomma marginatum, Hyalomma dromedarii, Hyalomma schulzei, and Hyalomma detritum) were found on the borders of Iran and Pakistan, with H. anatolicum being the most prevalent tick species. Anaplasma spp. and/or Ehrlichia spp. DNA was found in $68.3 \%$ of the engorged tick specimens $(n=256)$. Sequencing of a subset (12.6\%) of PCR-positive samples revealed Anaplasma ovis, Anaplasma marginale, and Ehrlichia ewingii DNA in 81.8\%, $9.1 \%$, and $9.1 \%$ of the ticks, respectively. To our knowledge, this is the first report of E. ewingii, an important human pathogen, in Iran.
\end{abstract}

Conclusions: Based on molecular analysis, three pathogenic Anaplasmataceae were detected in six Hyalomma spp. parasitizing cattle, goats and camels, confirming the presence of these pathogens along the Iran-Pakistan border.

Keywords: Anaplasmosis, Ehrlichiosis, Hard ticks, Iran, Pakistan, Tick-borne diseases

\section{Background}

Ticks are considered to be the second most common vector of human diseases worldwide after mosquitoes, but they are the most important vectors of disease-causing pathogens in domestic and wild animals. Indeed, ticks transmit a wide variety of pathogens, including viruses, bacteria and protozoa, to their vertebrate hosts [1].

For instance, anaplasmosis is caused by a number of established and emerging tick-borne pathogens,

*Correspondence: moshaghi@sina.tums.ac.ir

${ }^{1}$ Department of Medical Entomology and Vector Control, School of Public Health, Tehran University of Medical Sciences, Tehran, Iran

Full list of author information is available at the end of the article including Anaplasma phagocytophilum, Anaplasma marginale, Anaplasma ovis, Anaplasma centrale, Anaplasma bovis, Anaplasma capra, Anaplasma platys, and 'Candidatus Anaplasma camelii', which are found worldwide, particularly in tropical and subtropical regions, including Iran [2-6]. Anaplasma spp. may infect humans and a broad range of wild and domestic mammals, including horses, dogs, cats, deer, goats, sheep, cattle, camel, and other ruminants $[4,6,7]$. Ehrlichiosis caused by Ehrlichia spp. is another tick-borne disease [8], and some Ehrlichia spp. have been identified as pathogens in humans. For example, Ehrlichia chaffeensis causes human monocytic ehrlichiosis and Ehrlichia ewingii is an agent of human granulocytic ehrlichiosis [9]. The zoonotic 
nature of the human ehrlichiosis is supported by reports of natural infections with the same Ehrlichia spp. in dogs, deer, horses, and rodents [10]. Granulocytic ehrlichiosis in humans has been described in immunocompromised and immunocompetent patients, causing headache, fever, myalgia, vomiting, nausea, acute renal failure, thrombocytopenia, leukopenia and increased liver enzyme activities [11-13].

Iran has a variety of climates: a mild cold climate in the high mountains; continental and arid climates in the plateau; a mild and damp climate on the Caspian coast; and a hot desert climate on the southern coast and in the south-east. Each climate may provide conditions suitable for the development of different tick species, which probably explains the difference in the epidemiology of anaplasmosis and ehrlichiosis in different regions [14]. Sistan and Baluchistan Province in the south-east corner of Iran has a long border with Pakistan and Afghanistan, where infectious diseases do not respect international boundaries [15]. Animal husbandry is one of the main activities of the people in the province, and every week thousands of head of livestock, including sheep, goats, cows, camels, and buffaloes, cross the borders between the countries [16].

Although Anaplasma spp. and Ehrlichia spp. have been identified by molecular assays in livestock in Iran, their presence in their vectors has been much less studied. There have been only a few studies on the detection of Anaplasma spp. and Ehrlichia spp. in ticks in Iran, which reported the presence of infected ticks in the north and other regions of Iran $[14,17,18]$.

Ixodid ticks play an important role in maintaining Anaplasma spp. and Ehrlichia spp. in nature [19, 20]. Nonetheless, while Hyalomma spp. have been suggested as vectors of $A$. marginale [21], there has been little research on their possible involvement in Anaplasma spp. and Ehrlichia spp. transmission. Here, we report the occurrence of Hyalomma spp. infesting various domestic animals in the Iranian Province of Sistan and Baluchistan, with notes on Anaplasma spp. and Ehrlichia spp. infections in these ticks.

\section{Methods}

\section{Sample collection and tick identification}

The regions investigated include three districts of Sib \& Suran County (Hiduj district; geographical coordinates $27^{\circ} 00^{\prime} 02^{\prime \prime} \mathrm{N}, 62^{\circ} 07^{\prime} 01^{\prime \prime} \mathrm{E}$ ), Sarbaz County (Pishin district; geographical coordinates $\left.30^{\circ} 35^{\prime} 5.31^{\prime \prime} \mathrm{N}, 66^{\circ} 59^{\prime} 41.19^{\prime \prime} \mathrm{E}\right)$ and Chabahar County (Negour district; geographical coordinates $25^{\circ} 23^{\prime} 20.84^{\prime \prime} \mathrm{N}, 61^{\circ} 8^{\prime} 18.96^{\prime \prime} \mathrm{E}$ ), all of which are located in the south-east of Iran, close to the border with Pakistan. The collection of ticks was performed in three randomly selected major animal husbandry farms in each district, between November 2017 and late March 2018 , i.e. at the season when adult ticks are most active in the region. In total, 1124 ticks were collected from goats $(n=80)$, cattle $(n=34)$, and camels $(n=12)$. Tick collection was arbitrarily conducted, depending upon the availability of the domestic animals for a 15-min examination per animal, but efforts were made to obtain a widespread representative sample from the different animal species included in the study. All ticks were transferred to vials and labelled according to their geographical origin and the animal from which they were obtained. The collected ticks were subsequently transferred to the Entomology Laboratory in the School of Public Health at the Tehran University of Medical Sciences and were identified to species level, based on microscopic observation of external morphological characteristics according to the identification keys [22-24].

\section{DNA extraction}

After species identification, the ticks were sterilized by immersion in $70 \%$ alcohol, washed in distilled water, dried on filter paper in a laminar-flow hood, and then stored at $-80^{\circ} \mathrm{C}$ until the DNA extraction.

Individual ticks were frozen in liquid nitrogen and then ground in an Eppendorf microtube. The DNA was then extracted using the G-spin Genomic DNA Extraction Kit (iNtRON Biotechnology, South Korea), according to the manufacturer's instructions. The precipitated DNA samples were quantified using a spectrophotometer (Thermo Scientific ${ }^{\mathrm{TM}}$ NanoDrop ${ }^{\mathrm{TM}}$ One, Wilmington, DE, USA), and their integrity was assessed using $1 \%$ agarose gel electrophoresis. Then, the extracted DNA was suspended in sterile distilled water and stored at $-20^{\circ} \mathrm{C}$. Of the ticks collected, all the engorged ticks were analysed, and a subset $(n=50)$ of the unfed ticks were also tested for the presence of Anaplasma spp. and Ehrlichia spp.

\section{Molecular detection of Anaplasma spp. and Ehrlichia spp. in ticks}

The 16S rRNA gene of Anaplasma spp. and Ehrlichia spp. was amplified using the nested PCR protocol designed by Rar et al. [25]. The forward and reverse primers for initial reactions were Ehr1 (5'-GAA CGA ACG CTG GCG GCA AGC-3') and Ehr2 (5'-AGT $\mathrm{A}(\mathrm{T} / \mathrm{C}) \mathrm{C}$ G(A/G)A CCA GAT AGC CGC-5') and for nested reactions were Ehr3 (5'-TGC ATA GGA ATC TAC CTA GTA G-3') and Ehr4 (5'-CTA GGA ATT CCG CTA TCC TCT-3'). The size of final PCR products was 524 base pairs (bp). PCR reactions were performed in a $25 \mu \mathrm{l}$ reaction mixture, containing $12.5 \mu \mathrm{l}$ of the Hot Start Taq $2 \times$ Master Mix, $1 \mu$ of each of the forward and reverse primers, $2 \mu$ of DNA template 
and $7.5 \mu \mathrm{l}$ of nuclease-free water to bring the volume to $25 \mu$ l. PCR reactions were performed in a DNA Mastercycler Personal PCR machine (Eppendorf, Germany) and PCR conditions were: $15 \mathrm{~min}$ at $95{ }^{\circ} \mathrm{C}$ for initial denaturation, then $60 \mathrm{~s}$ at $94{ }^{\circ} \mathrm{C}$ for denaturing, $60 \mathrm{~s}$ at $57^{\circ} \mathrm{C}$ for annealing, and $60 \mathrm{~s}$ at $72{ }^{\circ} \mathrm{C}$ for extension for 35 cycles, and then a final extension for $10 \mathrm{~min}$ at $72{ }^{\circ} \mathrm{C}$. The products $(2 \mu \mathrm{l})$ of the first PCR were used as the template for the second PCR, which was carried out under the same conditions and reaction mixture as the first, except that nesting primers were used [25]. Two negative controls (one of double-distilled water and one of an un-infected tick DNA template) and a positive control (a confirmed sequenced A. bovis DNA isolated from a tick) were included in each PCR run. To ensure the presence of viable DNA, the barcoding region of the tick $C O I$ gene was used as endogenous control [26].

To assess the presence of expected bands for Anaplasma spp. and Ehrlichia spp., the PCR products were electrophoresed in a $1.5 \%$ agarose gel, and the size of each PCR product was estimated using a $100 \mathrm{bp}$ ladder and visualized with a UV transilluminator.

\section{DNA sequencing and phylogenetic analysis}

The positive PCR products were purified, and bidirectional DNA sequencing was performed by the Sanger method, using the same inner PCR primers that were used for nested PCR amplification. The sequences obtained were edited and assembled using Chromas (http://www.technelysium.com.au/chromas.html) and BioEdit [27] software to construct consensus sequences, which were then analysed using the NCBI Blast database (Nucleotide collection) (https://www. ncbi.nlm.nih.gov/). The consensus high-confidence sequences were aligned with other sequences that were available in GenBank, using multiple sequence alignments available in CLUSTAL Omega (https://www.ebi. ac.uk/Tools/msa/clustalo). For phylogenetic analysis, the representative sequences of Anaplasma spp. and Ehrlichia spp. obtained in this study were combined with a subset of available representative sequences of all Anaplasma spp. and E. ewingii, using Spiroplasma sp. sequences as an outgroup [28-31]. Details of these sequences are shown as supplementary data (Additional file 1: Table S1). All the DNA sequences used for alignment were cut to obtain a consistent region (470 bp), and phylogenetic analyses were performed using the MEGA 7 software [32]. The data were aligned and the maximum likelihood method was employed to construct a phylogenetic tree. The same program was utilized to evaluate the stability of the obtained tree through bootstrap analysis with 1000 replicates.

\section{Results}

Tick species and abundance

A total of 1124 hard ticks were collected which were classified into three genera: Hyalomma $(n=1020,90.7 \%)$, Rhipicephalus $(n=68,6.1 \%)$, and Dermacentor $(n=36$, $3.2 \%)$. All of the 1020 ticks collected were morphologically identified as belonging to one of six Hyalomma spp., with Hyalomma anatolicum being the most common species in all three districts. In detail, the tick species were found to be $H$. anatolicum $(n=462 ; 228$ from cattle and 234 from goats), Hyalomma asiaticum ( $n=143$; 87 from camels, 25 from goats, and 31 from cattle), Hyalomma marginatum ( $n=203 ; 134$ from cattle, 66 from goats and three from camels), Hyalomma dromedarii ( $n=188 ; 46$ from goats and 142 from camels), Hyalomma schulzei ( $n=17$ from goats), and Hyalomma detritum $(n=6$ from camels) (Table 1). The average number of ticks on camels, cattle, and goats were 19.8, 11.6, and 4.9 , respectively. The collected tick specimens were mix of unfed (75\%), partially fed (15.1\%), and fully engorged (9.9\%). Unfed were very small, often black or brown colour, partially engorged (partially swollen), which means the tick has had a partial blood meal, and engorged (swollen, usually blue-grey in colour) (Table 1).

\section{Anaplasma spp. and Ehrlichia spp. infections in ticks}

Using generic EHR primers, a subset $(n=50)$ of nonengorged tick specimens, and all of the 255 fully or partially engorged tick specimens, comprising 63 males (25\%) and 192 females (75\%), were tested for the presence of Anaplasma spp. and Ehrlichia spp. The tested specimens were representatives of the ticks collected from different animals in the three regions. The positive results were obtained with $68.6 \%$ (175 out of 255 ) of the engorged specimens, whereas non-engorged specimens were all negative. The species, number, and percentage of pathogen infection in Hyalomma spp. ticks at each collection site are shown in Table 2. A sub-set of positive PCR amplicons was sequenced and the consensus sequences were deposited in GenBank (accession numbers shown in Table 3). Details of the Anaplasma spp. and Ehrlichia spp.-positive samples are provided in Table 3.

\section{Sequence and phylogenetic analysis}

Analysis of the sequence data showed that the highest percentage of sequences obtained corresponded to A. ovis (18 out of $22,81.8 \%$ ). All of the strains of A. ovis detected in this study were identical, both to each other and to the other Iranian strains, and to the strains from China (GenBank: MG869525) and Russia (GenBank: KC484563). In addition to A. ovis, two A. marginale $(9.1 \%)$ and two E. ewingii (9.1\%) positive samples were detected. Sequences of $A$. marginale 
Table. 1 Details of Hyalomma spp. specimens collected from animals in Sistan and Baluchistan Province, south-east corner of Iran, 2017-2018

\begin{tabular}{|c|c|c|c|c|c|c|c|c|c|c|c|}
\hline \multirow[t]{2}{*}{ Location } & \multicolumn{3}{|c|}{$\begin{array}{l}\text { No. of animals } \\
\text { examined }\end{array}$} & \multirow[t]{2}{*}{ Tick species } & \multicolumn{3}{|c|}{ No. of ticks on animal } & \multirow[t]{2}{*}{ Subtotal } & \multirow[t]{2}{*}{ Male/female } & \multirow[t]{2}{*}{ U/PE/FE } & \multirow[t]{2}{*}{ Total } \\
\hline & $\mathrm{Ct}$ & Go & $\mathrm{Cm}$ & & $\mathrm{Ct}$ & Go & $\mathrm{Cm}$ & & & & \\
\hline \multirow[t]{3}{*}{ Chabahar } & 14 & 29 & 1 & Hyalomma marginatum & 41 & 36 & 0 & 77 & $19 / 58$ & $53 / 16 / 8$ & 312 \\
\hline & & & & Hyalomma anatolicum & 134 & 59 & 0 & 193 & $47 / 146$ & $149 / 24 / 20$ & \\
\hline & & & & Hyalomma asiaticum & 17 & 25 & 0 & 42 & $11 / 31$ & $30 / 8 / 4$ & \\
\hline \multirow[t]{4}{*}{ Sarbaz } & 13 & 23 & 4 & Hyalomma marginatum & 19 & 13 & 0 & 32 & $8 / 24$ & $26 / 2 / 4$ & 322 \\
\hline & & & & Hyalomma anatolicum & 43 & 132 & 0 & 175 & $44 / 131$ & 126/31/18 & \\
\hline & & & & Hyalomma dromedarii & 0 & 46 & 52 & 98 & $24 / 74$ & $80 / 7 / 11$ & \\
\hline & & & & Hyalomma schulzei & 0 & 17 & 0 & 17 & $5 / 12$ & $12 / 3 / 2$ & \\
\hline \multirow[t]{5}{*}{ Sib and Suran } & 7 & 28 & 7 & Hyalomma asiaticum & 14 & 0 & 87 & 101 & $25 / 76$ & $79 / 14 / 8$ & 386 \\
\hline & & & & Hyalomma dromedarii & 0 & 0 & 90 & 90 & $22 / 68$ & $64 / 12 / 14$ & \\
\hline & & & & Hyalomma detritum & 0 & 0 & 6 & 6 & $2 / 4$ & $4 / 0 / 2$ & \\
\hline & & & & Hyalomma marginatum & 75 & 17 & 3 & 95 & $24 / 71$ & $74 / 21 / 0$ & \\
\hline & & & & Hyalomma anatolicum & 51 & 43 & 0 & 94 & $24 / 70$ & $68 / 16 / 10$ & \\
\hline Total & 34 & 80 & 12 & & 394 & 388 & 238 & 1020 & $255 / 765$ & 765/154/101 & 1020 \\
\hline
\end{tabular}

$\mathrm{Ct}$, cattle; Go, goat; $\mathrm{Cm}$, camel; $\mathrm{U}$, unfed; $\mathrm{PE}$, partially engorged; $\mathrm{FE}$, fully engorged

Table. 2 Details of Anaplasmataceae infections in different Hyalomma spp. collected from Sistan and Baluchistan Province, south-east corner of Iran, 2017-2018

\begin{tabular}{|c|c|c|c|c|}
\hline Tick species & No. of collected samples & No. of specimens tested (\%) & Anaplasmataceae positive (\%) & $\begin{array}{l}\text { No. of } \\
\text { specimens } \\
\text { sequenced }\end{array}$ \\
\hline Hyalomma anatolicum & 462 & $114(24.7)$ & $78(67.8)$ & 7 \\
\hline Hyalomma asiaticum & 143 & $35(24.4)$ & $24(68.5)$ & 3 \\
\hline Hyalomma dromedarii & 188 & $47(25)$ & $32(68.1)$ & 4 \\
\hline Hyalomma marginatum & 204 & $52(25.4)$ & $36(69.2)$ & 4 \\
\hline Hyalomma detritum & 6 & $2(33.3)$ & $2(100)$ & 2 \\
\hline Hyalomma schulzei & 17 & $5(29.4)$ & $2(40)$ & 2 \\
\hline Total & 1020 & $255(25.0)$ & $175(68.3)$ & 22 \\
\hline
\end{tabular}

found in this study were identical to sequences from the USA, Brazil, Cuba, Iraq and China (GenBank: CP000030, CP023731, MK804764, MH551233, and KU586075, respectively). Similarly, the detected strains of $E$. ewingii obtained in this study were identical or highly similar to the isolates from Australia, the USA, Brazil, Thailand, and China (GenBank: NR_044747, NR_044747, HQ908082, NR_044747, and MN148615, respectively). The detected strains of $A$. marginale and or $E$. ewingii showed sequence similarities of $99-100 \%$ with sequences available in GenBank.

Phylogenetic analysis revealed that the Anaplasma/Ehrlichia spp. detected in this study clustered into four different clades, including (I) A. ovis, (II) A. marginale, (III) $A$. platys- $A$. phagocytophilum- $A$. odocoilei, and (IV) A. centrale-A. capra (Fig. 1). Both E. ewingii sequences obtained herein were associated with the branches of clade III.

\section{Discussion}

This is the first comprehensive study of the Hyalomma spp. ticks from domestic animals and their associated Anaplasma spp. and Ehrlichia spp. along the Iran-Pakistan border. The results show that domestic animals in this area are infested with at least six Hyalomma spp., in addition to ticks belonging to other genera, which were not identified to species level herein. Moreover, at least two Anaplasma spp. and one Ehrlichia sp. were detected in the collected ticks. These results are generally in agreement with previous observations in Pakistan and in other parts of Iran [17, 33-36].

Herein, more than $90 \%$ of livestock-infesting adult ticks belonged to the genus Hyalomma, which agrees with the 
Table. 3 Details of Anaplasma spp. and Ehrlichia spp. infections in Hyalomma spp. from three districts of Sistan and Baluchistan Province, south-east corner of Iran, 2017-2018

\begin{tabular}{|c|c|c|c|c|c|}
\hline Tick species & Tick sex & Host & District & Pathogen species & GenBank ID number \\
\hline Hyalomma anatolicum & Female & Cattle & Chabahar & Anaplasma ovis & MK310471 \\
\hline Hyalomma anatolicum & Female & Cattle & Sib and Suran & Anaplasma ovis & MK310472 \\
\hline Hyalomma anatolicum & Female & Cattle & Sib and Suran & Anaplasma ovis & MK310473 \\
\hline Hyalomma anatolicum & Male & Goat & Sib and Suran & Anaplasma ovis & MK310474 \\
\hline Hyalomma anatolicum & Female & Goat & Sarbaz & Anaplasma ovis & MK310475 \\
\hline Hyalomma anatolicum & Female & Goat & Sarbaz & Anaplasma ovis & MK310476 \\
\hline Hyalomma asiaticum & Female & Cattle & Sib and Suran & Anaplasma ovis & MK310477 \\
\hline Hyalomma asiaticum & Male & Goat & Sib and Suran & Anaplasma ovis & MK310478 \\
\hline Hyalomma asiaticum & Female & Cattle & Chabahar & Anaplasma ovis & MK310479 \\
\hline Hyalomma dromedarii & Female & Goat & Sarbaz & Anaplasma ovis & MK310480 \\
\hline Hyalomma dromedarii & Male & Camel & Sarbaz & Anaplasma ovis & MK310481 \\
\hline Hyalomma marginatum & Male & Cattle & Sib and Suran & Anaplasma ovis & MK310482 \\
\hline Hyalomma marginatum & Male & Goat & Chabahar & Anaplasma ovis & MK310483 \\
\hline Hyalomma marginatum & Female & Cattle & Chabahar & Anaplasma ovis & MK310484 \\
\hline Hyalomma detritum & Male & Camel & Sib and Suran & Anaplasma ovis & MK310485 \\
\hline Hyalomma detritum & Male & Camel & Sib and Suran & Anaplasma ovis & MK310486 \\
\hline Hyalomma schulzei & Female & Goat & Sarbaz & Anaplasma marginale & MK310487 \\
\hline Hyalomma schulzei & Male & Goat & Sarbaz & Anaplasma marginale & MK310488 \\
\hline Hyalomma anatolicum & Male & Cattle & Chabahar & Anaplasma ovis & MK310489 \\
\hline Hyalomma dromedarii & Female & Camel & Sib and Suran & Ehrlichia ewingii & MK310490 \\
\hline Hyalomma dromedarii & Male & Camel & Sib and Suran & Ehrlichia ewingii & MK310491 \\
\hline Hyalomma marginatum & Female & Cattle & Chabahar & Anaplasma ovis & MH480603 \\
\hline
\end{tabular}

result of other researchers in Baluchistan of Pakistan where 525 out of 529 (99.2\%) of the ticks belonged to this genus [37]. Among Hyalomma spp., H. anatolicum was the most common species and presented the widest geographical range. This three-host tick species was previously reported to be the most prevalent hard tick from different parts of Pakistan and Iran [17, 18, 33-35, $38-43]$.

The ecology of different Hyalomma spp. ticks may influence the risk of tick-borne diseases in the region [39, 41, 44-46]. The intense animal movements across Iranian regions and neighbouring countries may also facilitate the spread of these ticks. The infected ticks found in this study were feeding on the animals at the time of collection and were, therefore, potentially transmitting (or ingesting) Anaplasma spp. and E. ewingii while feeding. Therefore, the possibility that these ticks play a role in the transmission of these agents to domestic animals in the study area requires further investigation.

Except for E. ewingii, the pathogens found herein have previously been detected in ticks in several regions of Iran $[14,18,33,41-43]$. However, we found the prevalence of Hyalomma spp. ticks carrying Ehrlichia spp. or Anaplasma spp. to be $68 \%$, which is higher than previously reported from other parts of the country, including
$4.6 \%$ in the south-eastern and north-western regions [33], 25\% in the north [35], 43.84\% in Meshkin-Shahr, Ardebil Province [43], and 55.5\% in the four provinces of East Azerbaijan, Gilan, South Khorasan and Yazd [14]. These differences in tick infection rates could be related to several factors, including sampling methods, diagnostic methods, season, tick species, and feeding status of the ticks. Here, although the nested PCR technique used is known to be highly sensitive and specific, more nested PCR-positive samples should have been sequenced to determine the actual prevalence of Anaplasma spp. and Ehrlichia spp. infection in the ticks.

The results of this study, taken together with the above literature, have shown that different Hyalomma spp. could be involved in the transmission of pathogens to cattle, goats and camels in different regions of Iran. In addition to the Hyalomma spp. ticks, other ticks, including Rhipicephalus bursa, Rhipicephalus sanguineus sensu lato, Dermacentor marginatus, Haemaphysalis erinacei, and Ixodes ricinus have been reported as proven or putative vectors of different bacteria of the family Anaplasmataceae in Iran $[17,18,33,43]$.

The fact that no Anaplasma spp. or Ehrlichia spp. DNA was detected in the non-engorged specimens may suggest that there is little or no transovarial transmission of 


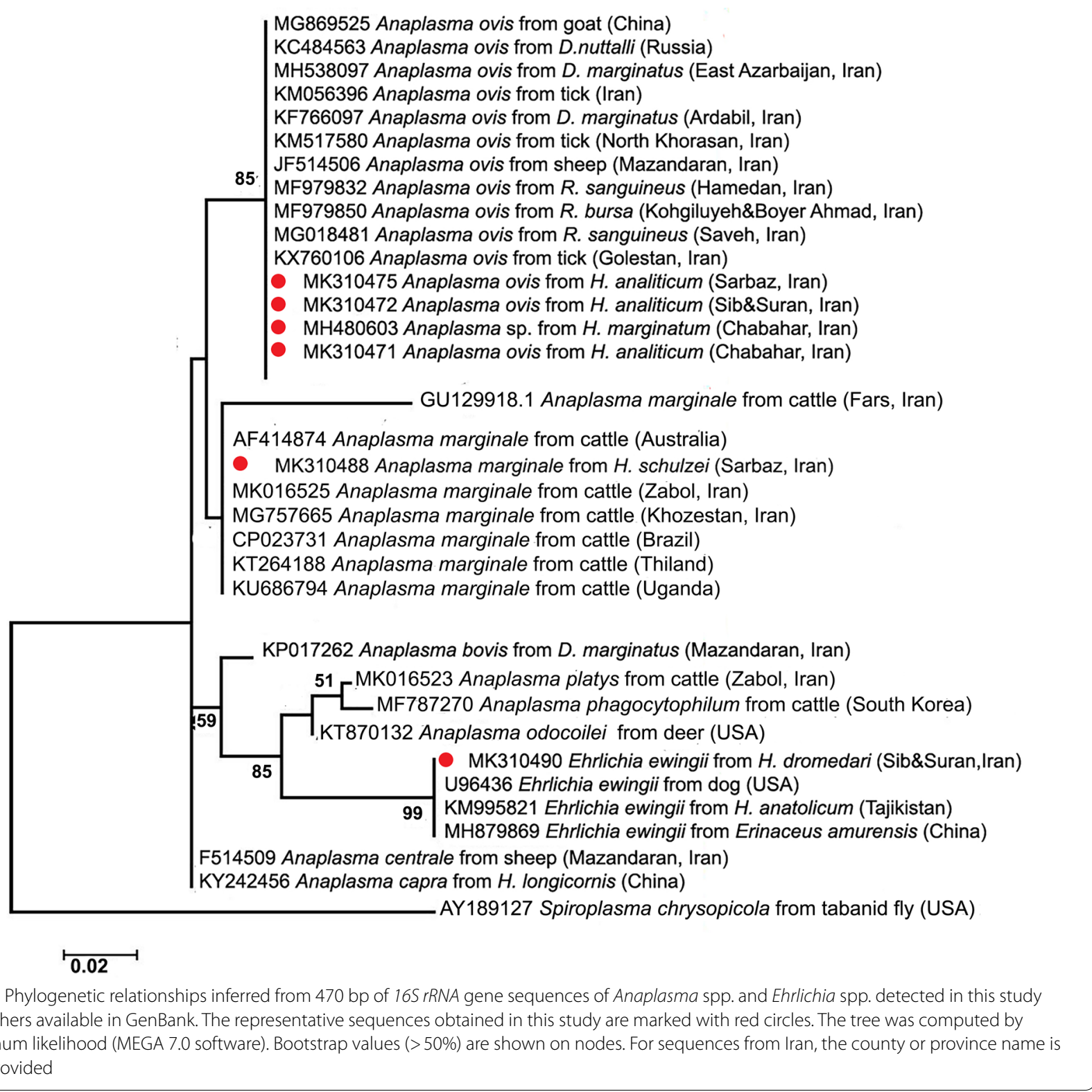

the bacteria in Hyalomma spp. ticks. Moore et al. [47] showed some evidence of transovarial transmission of $A$. ovis in Dermacentor nuttalli, although they did not detect any $A$. ovis DNA in larvae or nymphs. Another study [48] demonstrated the transovarial transmission of $A$. marginale in Rhipicephalus microplus, and that infected larvae can transmit the infection to susceptible hosts.

In this study, $A$. ovis was detected in five tick species: $H$. anatolicum, $H$. asiaticum, $H$. marginatum, $H$. dromedarii, and $H$. detritum, which were collected from cattle, goats, and camels. On the other hand, A. marginale and E. ewingii were found only in $H$. schulzei and $H$. dromedarii collected from goats and camels, respectively. Both $A$. ovis and $A$. marginale are important livestock pathogens [49], whereas E. ewingii is an important human pathogen $[10,50,51]$ and is reported for the first time in Iran. However, the presence of $E$. ewingii should be confirmed by sequencing other genes (e.g., groEL), which was not possible in this study. Anaplasma ovis is distributed worldwide and is an important agent of anaplasmosis in small ruminants [52, 53]. For instance, bovine anaplasmosis is hyper-endemic in Sistan and Balouchestan Province, where $80 \%$ of goats have been shown to be infected with $A$. ovis [54]. Indeed, both $A$. 
ovis and A. marginale are established as the main agents of goat anaplasmosis in Iran [54].

In addition to $A$. ovis and $A$. marginale, other studies at the borders of Iran with Afghanistan and with Pakistan have reported the presence of different Ehrlichia spp. and Anaplasma spp. [18, 36, 40, 55] including A. marginale, A. centrale, A. ovis, A. platys-like organism, and Ehrlichia minasensis, and two uncharacterized species, namely, Ehrlichia sp. (Multan) and Anaplasma spp. (BL099-6) [18, 36, 40].

\section{Conclusions}

In conclusion, we confirmed the presence of $A$. ovis, $A$. marginale and E. ewingii in Hyalomma spp. ticks collected from cattle, goats and camels on the Iran-Pakistan border. Further research is needed to confirm the role of these Hyalomma spp. and other ticks in the transmission of these pathogens in this region.

\section{Abbreviations}

PCR: Polymerase chain reaction; Bp: Base pair; COI: Cytochrome oxidase subunit one; UV: Ultraviolet; NCBI: National Center for Biotechnology Information.

\section{Supplementary Information}

The online version contains supplementary material available at https://doi. org/10.1186/s13071-021-04956-3.

Additional file 1: Table S1. Details of the bacterial species used for phylogenetic analysis in this study. D, Dermacentor, Rh, Rhipicephalus, Hy, Hyalomma, Ha, Haemaphysalis.

\section{Acknowledgements}

The authors are grateful to Farough Askani for his assistance in the field. We are grateful to Dr Miranda Thomas from ICGEB for her insightful suggestions and careful editing of the manuscript.

\section{Authors' contributions}

NC performed the whole study and wrote the manuscript. FK performed the phylogenetic analysis. MK helped in molecular analysis of data. JN made major contributions to study design and sample collection. MAO was the guarantor and analysed and interpreted the data, and was the major contributor in the editing of the manuscript. All authors read and approved the final manuscript.

\section{Funding}

This work has supported by Tehran University of Medical Sciences, Iran, grant number 29005.

\section{Availability of data and materials}

All data generated or analysed during this study are included in this published article. The sequence data are available at NCBI database.

\section{Declarations}

\section{Ethics approval and consent to participate}

All procedures were performed in accordance with the terms of the Iran Animals (Scientific Procedures) Act Project License and were approved by the Tehran University of Medical Sciences Ethical Review Committee, reference number: IR.TUMS.SPH.REC.1395.926. Due to social concerns, consent to participate was obtained verbally from the owners of the animals used in this study, which was approved by the committee.
Consent for publication

Not applicable.

\section{Competing interests}

The authors declare that they have no competing interests.

\section{Author details}

${ }^{1}$ Department of Medical Entomology and Vector Control, School of Public Health, Tehran University of Medical Sciences, Tehran, Iran. ${ }^{2}$ Department of Parasitology, Pasteur Institute of Iran, Tehran, Iran. ${ }^{3}$ Department of Public Health, School of Public Health, Zahedan University of Medical Sciences, Zahedan, Iran

Received: 4 May 2021 Accepted: 14 August 2021

Published online: 14 September 2021

\section{References}

1. De la Fuente J, Estrada-Pena A, Venzal JM, Kocan KM, Sonenshine DE. Overview: ticks as vectors of pathogens that cause disease in humans and animals. Front Biosci. 2008;13:6938-46.

2. Bakken JS, Dumler JS. Human granulocytic anaplasmosis. Infect Dis Clin North Am. 2015:29:341-55.

3. Ranjbar-Bahadori S, Eckert B, Omidian Z, Sadr Shirazi N, Parviz S. Babesia ovis as the main causative agent of sheep babesiosis in Iran. J Parasitol Res. 2012;110:1531-6.

4. Bastos AD, Mohammed OB, Bennett NC, Petevinos C, Alagaili AN. Molecular detection of novel Anaplasmataceae closely related to Anaplasma platys and Ehrlichia canis in the dromedary camel (Camelus dromedarius). Vet Microbiol. 2015;179:310-4.

5. Li H, Zheng YC, Ma L, Jia N, Jiang BG, Jiang RR, et al. Human infection with a novel tick-borne Anaplasma species in China: a surveillance study. Lancet Infect Dis. 2015;15:663-70.

6. Sazmand A, Harl J, Eigner B, Hodžić A, Beck R, Hekmatimoghaddam S, et al. Vector-borne bacteria in blood of camels in Iran: new data and literature review. Comp Immunol Microbiol Infect Dis. 2019;65:48-53.

7. Karlsen A, Vojtek B, Mojžišová J, Prokeš M, Drážovská M. Anaplasmosis in Animals. Folia. Veterinaria. 2020;64:17-26.

8. Ismail N, Bloch KC, McBride JW. Human ehrlichiosis and anaplasmosis. J Clin Lab Med. 2010;30:261-92.

9. Thomas RJ, Dumler JS, Carlyon JA. Current management of human granulocytic anaplasmosis, human monocytic ehrlichiosis and Ehrlichia ewingii ehrlichiosis. Expert Rev Anti Infect Ther. 2009;7:709-22.

10. Sainz Á, Roura X, Miró G, Estrada-Peña A, Kohn B, Harrus S, Solano-Gallego L. Guideline for veterinary practitioners on canine ehrlichiosis and anaplasmosis in Europe. Parasit Vectors. 2015;8:75.

11. Harris RM, Couturier BA, Sample SC, Coulter KS, Casey KK, Schlaberg R. Expanded geographic distribution and clinical characteristics of Ehrlichia ewingii infections United States. Emerg Infect Dis. 2016;22:862-5.

12. Heitman KN, Dahlgren FS, Drexler NA, Massung RF, Behravesh CB. Increasing incidence of ehrlichiosis in the United States: a summary of national surveillance of Ehrlichia chaffeensis and Ehrlichia ewingii infections in the United States, 2008-2012. Am J Trop Med Hyg. 2016;94:52-60.

13. Regunath H, Rojas-Moreno C, Olano JP, Hammer RD, Salzer W. Early diagnosis of Ehrlichia ewingii infection in a lung transplant recipient by peripheral blood smear. Transpl Infect Dis. 2017;19:e12652.

14. Tajedin L, Bakhshi H, Faghihi F, Telmadarraiy Z. High infection of Anaplasma and Ehrlichia spp. among tick species collected from different geographical locations of Iran. Asian Pac J Trop Dis. 2016;6:787-92.

15. Pourhossein B, Irani AD, Mostafavi E. Major infectious diseases affecting the Afghan immigrant population of Iran: a systematic review and metaanalysis. Epidemiol Health. 2015;37:e2015002.

16. Nematiniya A. Geocultural Inter-relations of Iranian and Pakistani Balochistan in the Globalization Era. J Subcontinent Res. 2013;15:135-52.

17. Hosseini-Vasoukolaei N, Oshaghi MA, Shayan P, Vatandoost $H_{\text {, }}$ Babamahmoudi F, Yaghoobi-Ershadi MR, et al. Anaplasma infection in ticks, livestock and human in Ghaemshahr, Mazandaran Province. Iran J Arthropod Borne Dis. 2014;8:204-11.

18. Jafarbekloo A, Bakhshi H, Faghihi F, Telmadarraiy Z, Khazeni A, Oshaghi MA, et al. Molecular detection of Anaplasma and Ehrlichia infection 
in ticks in borderline of Iran-Afghanistan. Vector Borne Zoonotic Dis. 2014;7:919-26.

19. Han R, Yang JF, Mukhtar MU, Chen Z, Niu QL, et al. Molecular detection of Anaplasma infections in ixodid ticks from the Qinghai-Tibet Plateau. Infect Dis Poverty. 2019;8:1-8.

20. Rar V, Golovljova L. Anaplasma, Ehrlichia, and "Candidatus Neoehrlichia" bacteria: pathogenicity, biodiversity, and molecular genetic characteristics, a review. Infect Genet Evol. 2011;11:1842-61.

21. Shkap V, Kocan K, Molad T, Mazuz M, Leibovich B, Krigel Y, et al. Experimental transmission of field Anaplasma marginale and the A. centrale vaccine strain by Hyalomma excavatum, Rhipicephalus sanguineus and Rhipicephalus (Boophilus) annulatus ticks. Vet Microbiol. 2009;134:254-60.

22. Estrada-Pena A, Bouattour A, Camicas J, Walker AR. Ticks of domestic animals in the Mediterranean region. Zaragoza: University of Zaragoza; 2004.

23. Hosseini-Chegeni A, Hosseine R, Tavakoli M, Telmadarraiy Z, Abdigoudarzi M. The Iranian Hyalomma (Acari: Ixodidae) with a key to the identification of male species. Persian J Acarol. 2013;2:503-29.

24. Hosseini-Chegeni A, Tavakoli M, Telmadarraiy Z. The updated list of ticks (Acari: Ixodidae \& Argasidae) occurring in Iran with a key to the identification of species. Syst Appl Acarol. 2019;24:2133-66.

25. Rar VA, Livanova NN, Panov WV, Kozlova IV, Pukhovskaya MN, Vysochina $\mathrm{NP}$, et al. Prevalence of Anaplasma and Ehrlichia species in Ixodes persulcatus ticks and small mammals from different regions of the Asian part of Russia. Int J Med Microbiol. 2008:298:222-30.

26. Folmer O, Black M, Hoeh W, Lutz R, Vrijenhoek R. DNA primers for amplification of mitochondrial cytochrome c oxidase subunit I from diverse metazoan invertebrates. Mol Mar Biol Biotechnol. 1994;3:294-9.

27. Hall TA. BioEdit: a user-friendly biological sequence alignment editor and analysis program for windows 95/98/NT. Nucleic Acids Symp Ser. 1999:41:95-8.

28. Lew AE, Gale KR, Minchin CM, Shkap V, de Waal DT. Phylogenetic analysis of the erythrocytic Anaplasma species based on 165 rDNA and GroEL (HSP60) sequences of A. marginale, A. centrale, and A. ovis and the specific detection of $A$. centrale vaccine strain. Vet Microbiol. 2003:92:145-60.

29. Goldman EE, Breitschwerdt EB, Grindem CB, Hegarty BC, Walls JJ, Dumler JS. Granulocytic ehrlichiosis in dogs from North Carolina and Virginia. J Vet Intern Med. 1998;12:61-70.

30. Whitcomb RF, French FE, Tully JG, Gasparich GE, Rose DL, Carle P, et al. Spiroplasma chrysopicola sp. nov., Spiroplasma gladiatoris sp. nov., Spiroplasma helicoides sp. no., and Spiroplasma tabanidicola sp. nov., from Tabanid (Diptera: Tabanidae) Flies. Int J Syst Evol Microbiol. 1997:47:713-9.

31. Gasparich GE, Whitcomb RF, Dodge D, French FE, Glass J, Williamson DL. The genus Spiroplasma and its non-helical descendants: phylogenetic classification, correlation with phenotype and roots of the Mycoplasma mycoides clade. Int J Syst Evol Microbiol. 2004;54:893-918.

32. Kumar S, Stecher G, Tamura K. MEGA7: molecular evolutionary genetics analysis version 7.0 for bigger datasets. Mol Biol Evol. 2016;33:1870-4.

33. Jafar Bekloo A, Ramzgouyan MR, Shirian S, Faghihi F, Bakhshi H, Naseri F, et al. Molecular characterization and phylogenetic analysis of Anaplasma spp. and Ehrlichia spp., isolated from various ticks in southeastern and northwestern regions of Iran. Vector Borne Zoonotic Dis. 2018;18:252-7.

34. Rehman A, Conraths FJ, Sauter-Louis C, Krücken J, Nijhof AM. Epidemiology of tick-borne pathogens in the semi-arid and the arid agroecological zones of Punjab province. Pakistan Transbound Emerg Dis. 2019;66:526-36.

35. Bekloo AJ, Bakhshi H, Soufizadeh A, Sedaghat MM, Bekloo RJ, Ramzgouyan MR, et al. Ticks circulate Anaplasma, Ehrlichia, Babesia and Theileria parasites in North of Iran. Vet Parasitol. 2017;248:21-4.

36. Jabbar A, Abbas T, Saddiqi HA, Qamar MF, Gasser RB. Tick-borne diseases of bovines in Pakistan: major scope for future research and improved control. Parasit Vectors. 2015;8:283.

37. Kasi KK, von Arnim F, Schulz A, Rehman A, Chudhary A, Oneeb M, et al. Crimean-Congo haemorrhagic fever virus in ticks collected from livestock in Balochistan. Pakistan Transbound Emerg Dis. 2020;67:1543-52.

38. Karim S, Budachetri K, Mukherjee N, Williams J, Kausar A, Hassan MJ, et al. A study of ticks and tick-borne livestock pathogens in Pakistan. PLoS Negl Trop Dis. 2017;11:e0005681.
39. Soosaraei M, Motavalli Haghi M, Etemadifar F, Fakhar M, Hosseini Teshnizi $\mathrm{S}$, et al. Status of Anaplasma spp., infection in domestic ruminants from Iran: a systematic review with meta-analysis. Parasite Epidemiol Control. 2020;11:e00173.

40. Biglari P, Bakhshi H, Chinikar S, Belqeiszadeh H, Ghaffari M, Javaherizadeh $S$, et al. Hyalomma anatolicum as the main infesting tick in an important livestock rearing region, central area of Iran. Iran J Public Health. 2018:47:742-9

41. Davari B, Alam FN, Nasirian H, Nazari M, Abdigoudarzi M, Salehzadeh A. Seasonal distribution and faunistic of ticks in the Alashtar county (Lorestan Province). Iran Pan Afr Med J. 2017;27:284-99.

42. Spitalska E, Namavari MM, Hosseini MH, Shad-Del F, Amrabadi OR, Sparagano OA. Molecular surveillance of tick-borne diseases in Iranian small ruminants. Small Ruminant Res. 2005:57:245-8.

43. Khazeni A, Telmadarraiy Z, Oshaghi MA, Mohebali M, Zarei Z, Abtahi SM. Molecular detection of Ehrlichia canis in ticks population collected on dogs in Meshkin-Shahr, Ardebil province. Iran J Biomed Sci Eng. 2013;6:1-5.

44. Choubdar N, Oshaghi MA, Rafinejad J, Pourmand MR, Maleki-Ravasan $\mathrm{N}$, Salehi-Vaziri M, et al. Effect of meteorological factors on Hyalomma species composition and their host preference, seasonal prevalence and infection status to Crimean-Congo haemorrhagic fever in Iran. J Arthropod Borne Dis. 2019;13:268-83.

45. Estrada-Peña A, Gray JS, Kahl O, Lane RS, Nijhoff AM. Research on the ecology of ticks and tick-borne pathogens-methodological principles and caveats. Front Cell Infect Microbiol. 2013;3:29.

46. Choubdar N, Karimian F, Koosha M, Oshaghi MA. An integrated overview of the bacterial flora composition of Hyalomma anatolicum, the main vector of CCHF. PLoS Negl Trop Dis. 2021;15:e0009480.

47. Moore TC, Pulscher LA, Caddell L, von Fricken ME, Anderson BD, Gonchigoo B, et al. Evidence for transovarial transmission of tick-borne rickettsiae circulating in Northern Mongolia. PLoS Negl Trop Dis. 2018;12:e0006696.

48. Estrada IA, García-Ortiz MA, Preciado de la Torre JF, Rojas-Ramírez EE, Hernández-Ortiz R, Alpírez-Mendoza F, Camarillo SDR. Transmission of Anaplasma marginale by unfed Rhipicephalus microplus tick larvae under experimental conditions. Rev Mex Cienc Pecu. 2020;11:116.

49. Alanazi AD, Nguyen VL, Alyousif MS, Manoj RR, Alouffi AS, Donato R, et al. Ticks and associated pathogens in camels (Camelus dromedarius) from Riyadh Province. Saudi Arabia Parasit Vectors. 2020;13:110.

50. Motaghipisheh S, Akhtardanesh B, Ghanbarpour R, Aflatoonian MR, Khalili M, Nourollahifard SR, et al. Ehrlichiosis in household dogs and parasitized ticks in Kerman-Iran: preliminary zoonotic risk assessment. J Arthropod Borne Dis. 2016;10:245-51.

51. Guo W-P, Huang B, Zhao Q, Xu G, Liu B, Wang YH, et al. Human-pathogenic Anaplasma spp., and Rickettsia spp., in animals in Xi'an China. PLoS Negl Trop Dis. 2018;12:e006916.

52. Cabezas-Cruz A, Gallois M, Fontugne M, Allain E, Denoual M, Moutailler $\mathrm{S}$, et al. Epidemiology and genetic diversity of Anaplasma ovis in goats in Corsica. France Parasit Vectors. 2019;12:3.

53. Kuttler KL. Anaplasma infections in wild and domestic ruminants: a review. J Wild Dis. 1984;20:12-20.

54. Yousefi A, Rahbari S, Shayan P, Sadeghi-dehkordi Z, Bahonar A. Molecular detection of Anaplasma marginale and Anaplasma ovis in sheep and goat in west highland pasture of Iran. Asian Pac JTrop Biomed. 2017;7:455-9.

55. Khodadadi N, Nabavi R, Sarani A, Saadati D, Ganjali M, Mihalca AD, et al. Identification of Anaplasma marginale in long-eared hedgehogs (Hemiechinus auritus) and their Rhipicephalus turanicus ticks in Iran. Ticks Tick Borne Dis. 2021;12:101641.

\section{Publisher's Note}

Springer Nature remains neutral with regard to jurisdictional claims in published maps and institutional affiliations. 